\title{
O trabalho docente no ensino superior e a saúde vocal: um estudo de revisão bibliográfica
}

\section{Eraldo Carlos Batista ${ }^{1}$ e Luís Alberto Lourenço de Matos ${ }^{2}$}

1 Doutorando em Psicologia pela PUC/RS, Mestre em Psicologia pela Universidade Federal de Rondônia, Especialista em Saúde Mental pela Universidade Dom Bosco. Professor da Faculdade São Paulo, Brasil. E-mail: eraldo.cb@hotmail.com

2 Professor Doutor do Programa de Pós Graduação em Psicologia - Mestrado Acadêmico (MAPSI) da Universidade Federal de Rondônia, Brasil. E-mail: lumatospvh@hotmail.com

RESUMO: O objetivo desta pesquisa foi fazer um levantamento de publicações referentes à saúde vocal do professor do ensino superior, no período de 2005 a 2013. A pesquisa foi delineada por meio de um estudo bibliográfico do tipo exploratório, no qual se buscaram artigos de periódicos indexados nos bancos de dados LILACS e SCIELO, obedecendo-se aos critérios de inclusão e exclusão pré-determinados. Foram encontrados seis artigos que abordavam a saúde vocal do professor universitário no período analisado, os quais focalizaram as investigações na qualidade de vida dos professores e a relação com a sua saúde vocal; nas relações entre o processo de trabalho docente e as condições sob as quais se desenvolve; no possível adoecimento físico, mental e vocal; e nos recursos vocais como estratégias que professores universitários utilizam em sala de aula. Os dados mostraram que é considerável o número de sintomas vocais apresentados nessa população, sendo os mais referidos: falhas na voz, rouquidão, esforço para falar, secura na garganta e pigarro. Há poucos estudos que contemplam a saúde vocal do professor universitário, mostrando que, em relação à prevenção e cuidados da voz dessa população, há necessidade de novas pesquisas para atender essa demanda.

Palavras-chave: Saúde Vocal. Professor Universitário. Trabalho Docente.

\section{Teaching work in higher education and the vocal health: a study of a bibliographic review}

ABSTRACT: The purpose of this research was to study publications concerning the vocal health of teachers who work in the higher education, between the years 2005 to 2013. This this research was designed through a bibliographic study of exploratory type in which it searched articles from journals indexed in LILACS and SciELO databases following the predeterminated inclusion and exclusion criteria. Six articles were found which addressed the vocal health of Professors during the period analyzed, which focused on researches about the quality of life for professors and the relationship with their vocal health; in the relationships between the teaching work process and the conditions under which it develops; the possibility of physical, mental and vocal illness; and devices which Professors use as vocal strategy in the classroom. Data showed the considerable number of vocal illness symptoms in this population and the most frequently mentioned are voice failures, hoarseness, effort to speak, dry throat and throat clearing. There are few studies on the vocal health of university teachers. This 
demonstrates that regarding the prevention and voice care of this population, there is a need of new researches to meet this demand.

Keywords: Vocal Health. Professor. Teaching Work.

\section{INTRODUÇÃO}

No momento atual, a voz em muitos contextos é vista como instrumento principal para a execução do trabalho de muitos profissionais. Concomitantemente a sua utilização, esses profissionais correm riscos ocupacionais diferenciados segundo cada contexto laboral e cultural.

Um dos profissionais apontado, consistentemente, como de risco vocal é o professor. Nesse esteio, as pesquisas científicas, ao relacionar profissão e transtornos de voz, concluem ser a docência uma das profissões com maior incidência de distúrbios desse tipo (SIMÕES; LATORRE, 2002; COOPER, 1974; SERVILHA; PEREIRA, 2008).

Considerando que a voz é uma exigência natural do trabalho desse profissional, pode-se afirmar que a sua saúde vocal é fator preponderante no desempenho de sua atividade laboral, uma vez que qualquer alteração ou desequilíbrio no uso dos recursos de comunicação poderá comprometer sua atuação profissional (VIEIRA; BEHLAU, 2009).

Mediante a prevalência de problemas vocais nessa categoria profissional, a relevância deste estudo encontra-se no fato de ser escassa a literatura que contempla a saúde vocal de docentes do ensino superior, quando comparado a outras áreas trabaIhistas (LIMA; LIMA-FILHO, 2009).

\subsection{Pesquisas sobre alterações na voz do professor}

Os recursos que o professor utiliza para obter a eficiência no processo de ensino são as estratégias de aprendizagem, o processo de avaliação e o clima emocional estabelecido na classe através da relação professor/aluno, por meio da qual esses se comunicam e se influenciam mutuamente. Nesse processo de ensino, a voz é o principal meio de comunicação do professor, tornando-se seu instrumento de trabalho, que deve ser saudável, ocorrer de maneira eficiente e sem esforço, ser interessante e clara, a fim de garantir a atenção do aluno (VIEIRA; BEHLAU, 2009).

Pesquisas sobre a voz do professor, em diversos países, têm buscado entender meIhor a relação da demanda de trabalho com os distúrbios vocais, sob o foco do uso diário e jornadas semanais, em diferentes situações. Há mais de uma década as pesquisas brasileiras também foram gradualmente aprofundadas na tentativa de compreender melhor a problemática vocal do professor, suas causas e consequências (SERVILHA; PEREIRA, 2008; VIEIRA; BEHLAU, 2009; LIMA; LIMA-FILHO, 2009; SIMOES; LATORRE, 2006; SERVILHA, MESTRE, 2010).

No que tange à ocorrência de alterações de voz (Disfonia) entre professores brasileiros, esses estudos trazem números bastante expressivos. A designação voz disfônica compreende um grande número de sintomas como desvios na qualidade vocal, esforço na emissão do som, perda de potência vocal, variações descontroladas da frequência fundamental, quebras da intensidade vocal e sensações desagradáveis na emissão (FREITAS, 2006). No professor, a prevalência de disfonia como consequência 
do uso indevido da voz aparece como maior frequência quando os dados são cotejados em comparação aos de outros profissionais (SMITH et al., 1997).

Números obtidos em um estudo com professores de Ensino Fundamental possibilitaram a constatação de que $52 \%$ dos participantes apresentavam alterações vocais, comprovadas por análise perceptivoauditiva feita por profissionais fonoaudiólogos (OLIVEIRA et al., 2005).

Estudo observacional transversal, realizado em 2000 em oito creches da cidade de São Paulo, com 93 educadoras, registrou que $80 \%$ apresentavam alteração vocal (SIMÕES; LATORRE, 2006).

Em Maceió, outro estudo, que avaliou a frequência de disfonia em 126 professores do Ensino Fundamental da Rede Municipal, referiu-se à ocorrência de $87,3 \%$ de disfonia na docência (ALVES; ARAÚJO; XAVIER NETO, 2010).

Em Criciúma, um estudo com 236 professores da Rede Municipal de Ensino que objetivou caracterizar a ocorrência de disfonia e determinar os fatores a ela associados em decorrência do exercício profissional, encontrou prevalência em $46,80 \%$ da população (LEMOS; RUMEL, 2005).

Outra questão presente nas pesquisas diz respeito aos hábitos que podem colaborar para o desgaste da voz do professor, tais como tabagismo, etilismo, hidratação insuficiente, gritos ou uso abusivo da voz, entre outros aspectos, hábitos que levam, entre outras questões, à rouquidão (SERVILHA; MESTRE, 2010; MARCHIORI; BARROS; OLIVEIRA, 2005).

Nesse esteio, pesquisa realizada com 40 professores do sexo masculino de uma empresa de cursos pré-vestibulares verificou que $77,5 \%$ dos participantes apresentaram queixas de sinais e sintomas vocais, sendo os mais citados: falhas na voz, rouquidão, esforço para falar, secura na garganta e pigarro (VIEIRA; BEHLAU, 2009). Na análise perceptivo-auditiva do referido estudo, observou-se que os professores apresentaram qualidade vocal discretamente alterada, sendo $35 \%$ do tipo rouca.

Contudo, observa-se que, mesmo tendo conhecimento de como cuidar da voz, os professores podem não conseguir preservar sua voz ao se defrontarem com os eventos inesperados da sala de aula, que algumas vezes tornam impossível o controle de seu comportamento vocal (VILKMAN, 2004).

\subsection{A saúde vocal do professor universitá- rio}

No que concerne ao professor universitário, pode-se dizer que muitas vezes é considerado de elite, pelas condições mais favoráveis de trabalho quando comparadas às dos professores de outros níveis de ensino (FABRÍCIO; KASAMA; MARTINEZ, 2009). Contudo, existem vários fatores no ambiente do ensino superior que também podem contribuir para a utilização inapropriada do uso da voz do professor, ocasionando deterioração de suas qualidades.

Aspectos ligados à organização do trabaIho como a jornada de trabalho, que exige alta demanda vocal, o número excedente de alunos entre outros, devem ser considerados como facilitadores potenciais das alterações vocais. Além disso, a presença do estresse, a competitividade e a responsabilidade são intensos fatores que podem predispor o professor a problemas de $\mathrm{VOZ}$ (SERVILHA; PEREIRA, 2008; FABRÍCIO; KASAMA; MARTINEZ, 2009). 
O trabalho docente exige o uso intensivo da fala, pois se trata de uma profissão em que trabalha com comunicação. Contudo, o uso inadequado da voz é um fator que contribui para os problemas relatados, observando-se ausência de preparação do professor para usar adequadamente a voz.

Pesquisa realizada com 189 docentes de uma Universidade Federal teve como objetivo verificar as relações entre o processo de trabalho docente, as condições sob as quais ele se desenvolve e o possível adoecimento físico e mental dos professores (LIMA; LIMA-FILHO, 2009). Os resultados desse estudo verificaram que as queixas apresentadas pelos professores estavam associadas às consequências negativas pelo uso intensivo da voz.

Dessa forma, o objetivo deste estudo foi fazer um levantamento das publicações sobre a saúde vocal do professor universitário, através de revisão da literatura especializada num período entre 2005 e 2013, que corresponde a oito anos.

\section{MÉTODO}

A proposta partiu do delineamento de um estudo bibliográfico de natureza exploratória, que aborda a temática da voz do professor do ensino superior. A pesquisa bibliográfica constitui-se da releitura do tema em estudo, a partir de livros e artigos científicos (GIL, 2008). A revisão de literatura foi feita em três etapas: levantamento do material, classificação e análise de conteúdo.

Seguindo a proposta metodológica, procurou-se: levantar as publicações no período de 2005 a 2013, indexadas ou catalogadas nas bibliotecas eletrônicas: Literatura Latino Americana e do Caribe em Ciências da Saúde (LILACS) e Scientific Electronic Library Online (SciELO), utilizando os seguintes descritores: saúde vocal do professor universitário, a voz do professor, condição vocal do professor, voz do professor universitário, sobre os quais foram encontrados 111 artigos, entre os quais apenas seis foram selecionados para a análise.

Todas as produções foram digitadas em planilha específica, considerando, além de título e autores, o ano e o tipo de produção. Em seguida, foram categorizados quanto a autor, título, tipo de pesquisa, ano e periódico de publicação.

Para a obtenção do número total de artigos a serem analisados, foram utilizados os seguintes critérios de inclusão: artigos publicados na íntegra no período de 2005 a 2013, aqueles cujos resumos apresentavam o professor do ensino superior como sujeito; os disponibilizados em língua portuguesa, aqueles que possuíam pelo menos dois dos descritores selecionados. Utilizaram-se, também, os seguintes critérios de exclusão: aqueles cujos resumos não apresentavam 0 professor universitário como sujeito e/ou não descreviam suas alterações vocais; e os artigos não disponíveis na íntegra.

Após a leitura inicial dos resumos obtidos para constatar a coerência com o tema a ser pesquisado e obedecendo-se aos critérios explicitados anteriormente, foram encontrados, no total, seis artigos, sendo dois indexados na biblioteca SciELO e quatro na biblioteca virtual LILACS, os quais foram lidos na íntegra.

\section{RESULTADOS}

Serão apresentados a seguir os resultados descritivos individuais dos artigos encontrados, para oferecer uma visão mais 
pormenorizada dos resultados obtidos por eles, propiciar comparações e se obter uma visão global desse estudo.

No Quadro 1, abaixo, foram relacionadas informações sobre os seis artigos, quanto a autor, título, ano da publicação, tipo de pesquisa e periódico em que cada um foi publicado.

Quadro 1 - Artigos sobre saúde vocal de professores universitários, publicados no período de 2005 a 2013.

Frame 1 - Articles about vocal health of university professors, published between 2005-2013.

\begin{tabular}{|c|c|c|c|c|c|}
\hline № & AUTORES & TITULO & ANO & $\begin{array}{c}\text { TIPO DE } \\
\text { PESQUISA }\end{array}$ & $\begin{array}{l}\text { PERIÓ- } \\
\text { DICO }\end{array}$ \\
\hline 01 & $\begin{array}{l}\text { SERVILHA; } \\
\text { ARBACH. }\end{array}$ & $\begin{array}{l}\text { Avaliação do efeito de } \\
\text { assessoria vocal com profes- } \\
\text { sores universitários }\end{array}$ & 2013 & $\begin{array}{c}\text { Quantitati- } \\
\text { va }\end{array}$ & $\begin{array}{l}\text { Distúrb } \\
\text { Comun, }\end{array}$ \\
\hline 02 & $\begin{array}{l}\text { SERVILHA; } \\
\text { PEREIRA. }\end{array}$ & $\begin{array}{l}\text { Condições de trabalho, } \\
\text { saúde e voz em professores } \\
\text { universitários. }\end{array}$ & 2008 & $\begin{array}{c}\text { Quantitati- } \\
\text { va. }\end{array}$ & $\begin{array}{l}\text { Rev. } \\
\text { Ciênc. } \\
\text { Méd., }\end{array}$ \\
\hline 03 & $\begin{array}{l}\text { SERVILHA; } \\
\text { MONTEI- } \\
\text { RO. }\end{array}$ & $\begin{array}{l}\text { Estratégias para obter a } \\
\text { atenção discente no contex- } \\
\text { to universitário: O papel da } \\
\text { voz do professor }\end{array}$ & 2007 & Qualitativa & $\begin{array}{l}\text { Distúrb } \\
\text { Comun, }\end{array}$ \\
\hline 04 & $\begin{array}{l}\text { FERREIRA } \\
\text { et al.; }\end{array}$ & $\begin{array}{l}\text { Professores universitários: } \\
\text { descrição de características } \\
\text { vocais e posturais }\end{array}$ & 2011 & $\begin{array}{c}\text { Quantitati- } \\
\text { va }\end{array}$ & $\begin{array}{l}\text { Distúrb } \\
\text { Comun, }\end{array}$ \\
\hline 05 & $\begin{array}{l}\text { FABRÍCIO; } \\
\text { KASAMA; } \\
\text { MARTINEZ. }\end{array}$ & $\begin{array}{l}\text { Qualidade de vida relaciona- } \\
\text { da à voz de professores } \\
\text { universitários }\end{array}$ & 2009 & $\begin{array}{c}\text { Quantitati- } \\
\text { va }\end{array}$ & $\begin{array}{c}\text { Rev. } \\
\text { CEFAC, }\end{array}$ \\
\hline 06 & $\begin{array}{l}\text { SERVILHA; } \\
\text { ROCCON. }\end{array}$ & $\begin{array}{l}\text { Relação entre voz e qualida- } \\
\text { de de vida em professores } \\
\text { universitários }\end{array}$ & 2009 & $\begin{array}{c}\text { Quantitati- } \\
\text { va }\end{array}$ & $\begin{array}{c}\text { Rev. } \\
\text { CEFAC. }\end{array}$ \\
\hline
\end{tabular}

Fonte: Bancos de dados LILACS E ScieLO, 2014

O primeiro artigo Avaliação do efeito de assessoria vocal com professores universitários trata de um estudo de assessoria vocal com 12 professores universitários. 0 trabaIho envolveu sete encontros com periodicidade semanal abordando: saúde vocal (comportamentos e atitudes que preservam a voz, uso da voz em sala de aula e amplificação sonora), técnicas vocais (aquecimento/desaquecimento, ressonância, projeção e modulação vocais) e coordenação respiração-fonação (SERVILHA; ARBACH, 2013).

$\mathrm{O}$ protocolo Índice de Desvantagem Vocal - IDV (BEHLAU; SANTOS; OLIVEIRA, 2011) foi aplicado no primeiro e no último dia da assessoria e seus valores comparados e tomados como parâmetros para se avaliar o efeito da assessoria vocal. Os resultados detalhados neste estudo e a evolução obtida pelos professores confirmam que a abordagem fonoaudiológica se mostra benéfica no desenvolvimento da autopercepção dos professores na relação saúde, docência e voz e fortalece-os como agentes de seu bem-estar. O estudo concluiu que a assessoria vocal mostrou efeitos positivos sobre a voz e o bem-estar dos professores, constatados pela redução dos escores geral e das subescalas do IDV, em especial na dimensão emocional.

O segundo artigo Condições de trabalho, saúde e voz em professores universitários (SERVILHA; PEREIRA, 2008) teve como objetivo verificar as relações entre o processo de trabalho docente, as condições sob as quais ele se desenvolve e o possível adoecimento físico e mental dos professores em uma Universidade Federal. Para tanto, foi conduzida uma pesquisa exploratória junto a 189 professores, cujos resultados mostraram que os docentes apresentam exaustão emocional, considerando a elevada manifestação de sintomas, tais como nervosismo, estresse, cansaço mental, esquecimento, insônia, alteração vocal, entre outros.

O terceiro artigo Estratégias para obter a atenção Discente no contexto universitário: O papel da voz do professor (SERVILHA; MONTEIRO, 2007) objetivou investigar as estratégias que professores universitários utilizam em sala de aula para obter a atenção dos alunos, com destaque para os recursos vocais. Participaram 18 professores, que ministram aulas teóricas para alunos de Fonoaudiologia de uma universidade do interior do Estado de São Paulo, os quais responderam a uma entrevista semiestruturada com questões sobre identificação, dados de carreira docente e recursos utiliza- 
dos para obter a atenção dos alunos em sala de aula. Os resultados mostraram uso variado de técnicas de ensino, porém, com predomínio da aula expositiva. As estratégias para obter a atenção do aluno foram reunidas em três modalidades:

a) Recursos internos ao professor como linguagem bem estruturada, definição articulatória, variação de frequência e intensidade vocal, uso de pausas e ênfases, contato visual com os alunos, pedido de atenção ou silêncio e uso de gestos;

b) Recursos externos ao professor, como a utilização de equipamentos audiovisuais; e

c) Relação teoria-prática, na qual os professores contextualizam o assunto para o aluno, trazendo para a sala de aula sua experiência.

Diante da ineficácia dessas estratégias, os professores optavam por mudar a dinâmica da aula, conversar com os alunos e suspender o discurso para criar um clima de expectativa. $O$ estudo concluiu que os professores valorizaram os conteúdos, o tipo de aula e o uso de recursos audiovisuais na relação professor-aluno e que os recursos vocais foram lembrados e utilizados como estratégia para captar a atenção discente.

O quarto artigo Professores universitários: descrição de características vocais $e$ posturais (FERREIRA et al. 2011) objetivou descrever as características de voz e postura de professores universitários. Participaram do estudo quatro professores universitários, submetidos à avaliação de voz e postura; para coleta de dados, utilizou-se a autorreferência. Na avaliação perceptivoauditiva da voz, nenhum dos sujeitos apresentou alteração de voz. Na autoavaliação, nenhum dos sujeitos fez referência à des- vantagem vocal, dado compatível com a avaliação perceptivo-auditiva.

Os autores concluíram que os resultados não permitiram afirmar que as alterações posturais associadas ao tempo de profissão e ao envelhecimento podem potencializar o surgimento de alteração de voz em professores universitários. Contudo, nesse estudo perceberam que existe uma relação entre voz e postura.

No quinto artigo, Qualidade de vida relacionada à voz de professores universitários, (FABRÍCIO; KASAMA; MARTINEZ, 2009) foi observada a qualidade de vida relacionada à voz dos docentes da Faculdade de Medicina de Ribeirão Preto da Universidade de São Paulo (FMRP-USP). Utilizando-se de uma abordagem quantitativa, o estudo usou como instrumento de coleta de dados o Protocolo de Qualidade de Vida em Voz (QVV) (BEHLAU et al. 2001) e um questionário que investigou sintomas vocais, uso da voz e atitudes diante dos sintomas.

Os resultados registraram que $82 \%$ dos docentes participantes alcançaram escores iguais a 100, para o domínio sócio emocional; 38\%, para o domínio físico; e 38\%, para o escore total. Uma grande parte (31\%) considera sua voz "muito boa", mas se deve considerar que $26 \%$ dos entrevistados não avaliaram sua voz. Com relação às atitudes que os docentes tomam frente a um problema vocal, $53 \%$ relataram diminuir o uso da voz.

Os sintomas de maior incidência relatados pelos docentes foram garganta seca, tosse e perda de voz. Assim, concluíram que não existia correlação entre satisfação vocal e alto índice de qualidade de vida, porém observou-se uma prevalência elevada de sintomas vocais, demonstrando a necessi- 
dade de ações preventivas e de orientação vocal para esses professores.

O sexto artigo Relação entre voz e qualidade de vida em professores universitários (SERVILHA; ROCCON, 2009) investigou o impacto da voz na qualidade de vida de professores e compararam seus resultados com a avaliação fonoaudiológica. Desse estudo participaram 21 professores universitários, $77 \%$ mulheres e $23 \%$ homens, com idade média de 48 anos, os quais preencheram o protocolo QVV e foram filmados para a avaliação fonoaudiológica, nos aspectos corporais e vocais.

Os resultados mostraram que os docentes classificaram suas vozes como boa $(42,85 \%)$, razoável $(38,09 \%)$ e muito boa e ruim, igualmente, $(9,52 \%)$. O Domínio Físico apresentou escore médio de 78,18, com destaque para a dificuldade em falar alto ou ser ouvido em ambientes ruidosos e ter problemas no trabalho ou desenvolver a profissão por causa da voz. No Domínio Sócio Emocional, o escore médio foi 88,98 , com destaque para demonstração de ansiedade ou frustração por causa da voz. O Domínio Global teve média de 82,61. Na avaliação fonoaudiológica, constataram-se mais vozes adaptadas $(61,90 \%)$ que alteradas (38,09\%), apresentando restrição na projeção e modulação ou rouquidão. A comparação entre a autoavaliação vocal, a avaliação fonoaudiológica e a qualidade de vida percebeu-se mais consenso que divergências.

Assim, os autores concluíram que o impacto da voz sobre a qualidade de vida foi baixo e que houve coerência entre os resultados do QVV e a avaliação fonoaudiológi$\mathrm{ca}$, indicando percepção apropriada dos docentes em relação à própria voz.

\section{DISCUSSÃO}

Quanto aos autores, a maioria dos artigos encontrados (quatro) tem como autor principal Emilse Aparecida Merlin Servilha, fonoaudióloga, Doutora em Psicologia, Docente da Faculdade de Fonoaudiologia da Pontifícia Universidade Católica de Campinas, na condição de líder da pesquisa publicada. A referida autora é referência nacional nessa discussão, citada em vários trabaIhos que abordam a temática. Os outros dois artigos selecionados também têm como autores principais pesquisadores com formação em fonoaudiologia. Nesse sentido, constata-se um viés carente de estudos sob a ótica da psicologia, ou seja, sobre as consequências psicoemocionais nos professores universitários que apresentam alterações vocais.

No que se refere à natureza das pesquisas, a maioria dos estudos (cinco) utilizou a pesquisa quantitativa como abordagem metodológica. Apenas o artigo Condições de trabalho, saúde e voz em professores universitários (SERVILHA; PEREIRA, 2008) teve a pesquisa qualitativa como método. Portanto, observa-se a necessidade de abordagens qualitativas que preencham as lacunas existentes nesses estudos. Pesquisas baseadas em questionários respondidos e completados pelos próprios respondentes, como é o caso da maioria dos artigos investigados, possibilitam a ocorrência de viés de autorrelato (BEHLAU et al. 2001).

Dos artigos analisados, dois discutiram a qualidade de vida dos professores e sua relação com a sua saúde vocal (FABRÍCIO; KASAMA; MARTINEZ, 2009; SERVILHA; ROCCON, 2009). Nesses estudos, os pesquisadores utilizaram o protocolo QVV que é um instrumento desenvolvido para medir a 
relação da voz com a qualidade de vida, o qual já foi traduzido, adaptado e validado para a língua portuguesa. Trata-se de um protocolo com 10 itens, considerando três domínios: sócio emocional, físico e global.

Embora os resultados desses estudos tenham revelado que os docentes participantes apresentaram boa qualidade de vida associada à voz, segundo a avaliação do $Q V V$, em ambos foi evidenciada uma prevalência elevada de sintomas vocais. Considerando que a qualidade de vida relacionada à voz é um importante auxílio para o entendimento da percepção que as pessoas possuem em relação à sua saúde vocal e de suas reações perante as alterações na voz, esses resultados demonstram a necessidade de ações preventivas e de orientação vocal para esses professores.

Os demais artigos abordaram respectivamente sobre as relações entre o processo de trabalho docente, as condições sob as quais ele se desenvolve e o possível adoecimento físico, mental e vocal; os recursos vocais como estratégias que os professores universitários utilizam em sala; e as características de voz e postura deles (SERVILHA; PEREIRA, 2008; LIMA; LIMA-FILHO, 2009; SERVILHA; ARBACH, 2013; SERVILHA; MONTEIRO, 2007; FERREIRA et al., 2011).

Quanto ao adoecimento mental nos professores que apresentaram alterações vocais, o estresse e a ansiedade foram os problemas que mais se destacaram. Esses sintomas podem estar associados às condições de trabalho não favoráveis ao trabalho docente, uma vez que fatores presentes no ambiente de trabalho e na sua organização, como ruído na sala de aula, a qualidade acústica da sala, ausência de um lugar para descanso, número de alunos por turma, quantidade de turmas para as quais leciona, carga horária, anos de magistério, entre outros podem levar ao desgaste do professor, trazendo prejuízos a sua saúde em geral, destacando-se a vocal (BRAGA JUNIOR, 2013). Contudo, os estudos apontam que os sinais e sintomas mais facilmente interpretados em sua provável relação com problemas de saúde vocal pelos professores são aqueles que provocam sensações físicas.

No que concerne às estratégias de aula utilizadas pelo professor universitário, a literatura encontrada afirma que essas estratégias, quando não eficazes, podem se tornar um dos fatores que contribui para 0 adoecimento vocal. A aula expositiva, muito utilizada nos diferentes níveis de ensino, parece predispor ao abuso vocal, pois o professor fala mais e mais alto para alcançar toda a classe e nem sempre permite a participação dos alunos (SERVILHA; MONTEIRO, 2007). Também, pontua-se a importância dos recursos vocais do professor, mais especificamente uma comunicação clara e objetiva com voz flexível.

Ainda se pode observar que fatores inerentes ao ambiente, tanto os internos quanto os externos, expõem o professor a outros agentes agressores em seu ambiente de trabalho que podem influenciar a sua saúde vocal, provocando a competição sonora e exigindo maior esforço e demanda vocal do professor (MARÇAL; PERES, 2011).

Nessa competição sonora fica evidente que o professor, por sua vez, necessita sobrepor a sua voz aos demais ruídos, provocando, involuntariamente, o aumento no volume de sua voz. Assim, a intensidade da voz foi descrita pelos artigos analisados como promotora de desgaste vocal. Nesse sentido, os professores precisam ser orientados sobre estratégias que substituam a 
forte intensidade da voz e promovam uma condição facilitadora para socializar e produzir o conhecimento (SCHWARZ; CIELO, 2005; SERVILHA; PEREIRA, 2008). Salas quentes, mal ventiladas, presença de poeira, sujeira, pó de giz, ruído interno e externo são condições que podem predispor o sujeito a irritações laríngeas, competição sonora e uso abusivo ou inadequado da voz, - que ocasiona alterações vocais (PENTEADO, 2007).

Essa intensidade diz respeito às modificações da voz ao longo do dia e são melhores observadas ao seu final, com a deterioração de suas qualidades, surgindo a rouquidão e a necessidade de esforço para a sua produção. O uso incorreto da voz, de forma mais relevante em situação profissional, que requer sua utilização por longos períodos, agride a laringe e as pregas vocais com consequente aparecimento de sintomas e sensações negativas como rouquidão, secura na garganta, pigarro e fadiga vocal (SERVILHA; ARBACH, 2013).

Em suma, os artigos aqui apresentados mostraram que existem múltiplos fatores que intervêm no uso da voz do professor universitário: as condições ambientais, os hábitos vocais do professor e aspectos de saúde docente. Por fim, de modo ainda sucinto, foram apontadas algumas estratégias que possibilitam ao professor prevenir a sua saúde vocal e, consequentemente, ter boa qualidade de vida.

\section{CONSIDERAÇÕES FINAIS}

O objetivo deste estudo foi fazer um levantamento das publicações sobre as alterações vocais decorrentes do trabalho docente universitário. Focalizou-se nos fatores inerentes às alterações vocais do professor universitário, no exercício da profissão, considerando-se que a voz é fundamental na comunicação e na relação interpessoal, importante para a promoção da saúde e da qualidade desse profissional, e que problemas a ela relacionados podem interferir no desempenho e na qualidade do seu trabaIho.

Os resultados mostraram que essa população apresenta elevado índice de sintomas vocais, sendo os mais referidos: falhas na voz, rouquidão, esforço para falar, secura na garganta e pigarro. Ainda apresentaram as adequações nos parâmetros de voz e fala e no uso de recursos não verbais utilizados em sala de aula, sendo o uso de gestos, o contato visual direcionado e a interação com os alunos, os mais utilizados.

Dessa forma, fazem-se necessários avanços nas ações de criação de programas que promovam intervenções na saúde vocal docente. Neste caso, é fundamental que o processo educativo inicialmente esteja calcado no objetivo de promoção da informação sobre a prevenção e tratamento da saúde vocal do professor. Sendo assim, é imprescindível a implantação de cursos, palestras, oficinas, consultorias com o objetivo de desenvolver o conhecimento vocal do professor como requisito para sua saúde.

$\mathrm{Na}$ busca bibliográfica, pode-se notar que a maioria dos estudos sobre a saúde vocal do professor tem sido realizada com docentes do ensino regular, das séries iniciais, ensino fundamental e médio. Ou seja, há poucos artigos nas bases investigadas que abordam a saúde vocal do docente do ensino superior. Assim, é possível sugerir a realização de novos estudos que verifiquem o impacto de ações que atuem sobre os condicionantes e determinantes da saúde vocal do professor universitário. 
As limitações deste estudo estão relacionadas ao número reduzido de artigos científicos encontrados, cujo objeto de pesquisa fosse a saúde vocal do professor universitário, dado que justifica a continuidade de investigações sobre essa temática.

\section{REFERÊNCIAS}

ALVES, L. P.; ARAÚJO, L. T. R.; XAVIER NETO, J. A. Prevalência de queixas vocais e estudo de fatores associados em uma amostra de professores de ensino fundamental em Maceió, Alagoas, Brasil. Rev. bras. Saúde ocup., São Paulo, v. 35, v. 121, p. 168-175, 2010.

BEHLAU, M. et al. Avaliação de voz. In: BEHLAU, M. Voz: o livro do especialista. v. 1. Rio de Janeiro: Revinter, 2001. p. 120-23, 2001.

BEHLAU, M.; SANTOS, L. M. A.; OLIVEIRA, G. Cross-cultural adaptation and validation of the voice handicap index into brazilian portuguese. J Voice, v. 25, n. 3, p. 354-9, 2011. BRAGA JUNIOR, F.V. Saúde vocal e docência no ensino superior. 2013 [Dissertação mestrado] Universidade Federal Rural do SemiÁrido - UFERSA

COOPER, M. Modernas técnicas de reabilitación vocal. Buenos Aires: Panamericana; 1974.

FABRÍCIO, M. Z.; KASAMA, S. T.; MARTINEZ, E. Z. Qualidade de vida relacionada à voz de professores universitários. Rev. CEFAC, São Paulo, v. 12, n. 2, p. 183-08, 2009.

FERREIRA, L. P. et al. Professores universitários: descrição de características vocais e posturais. Distúrb Comun, São Paulo, v. 23, n. 1, p. 43-49, abril, 2011.

FREITAS, S. V. Disfonia em professoras do primeiro ciclo do ensino básico. Arquivos de Medicina, v. 20, n. 5-6, p. 143-52, 2006.
GIL, A. C. Métodos e técnicas de pesquisa social. 6. ed. São Paulo: Atlas, 2008.

LEMOS, S.; RUMEL, D. Ocorrência de disfonia em professores de escolas públicas da rede municipal de ensino de Criciúma - SC. Revista Brasileira de Saúde Ocupacional, São Paulo, v. 30, n. 112, p. 07-13, 2005.

LIMA, M. F. E. M.; LIMA-FILHO, D. O. Condições de trabalho e saúde do/a professor/a universitário/a. Ciênc. cogn., v.14, n.3, p. 62-82, 2009.

MARÇAL, C. C. B.; PERES, M. A. Alteração vocal auto referida em professores: prevalência e fatores associados. Rev Saúde Pública, v. 45, n. 3, p. 03-11, 2011.

MARCHIORI, F.; BARROS, M. E. B.; OLIVEIRA, S. P. Atividade de trabalho e saúde dos professores: um programa de formação como estratégias de intervenção nas escolas. Trab Educ Saúde, v. 3, n. 1, p. 143-70, 2005.

OLIVEIRA, M. L. et al. Triagem vocal em professores da Rede de Ensino: 1a a 4a séries na cidade de Três Rios-RJ. Rev. CEFAC. v. 7, n. 4, p. 509-13, 2005.

PENTEADO, R. Z. Relações entre saúde e trabalho docente: percepções de professores sobre saúde vocal. Rev Soc Bras Fonoaudiol., v. 12 n.1, p.18-22, 2007.

SCHWARZ, K.; CIELO, C. A. A voz e as condições de trabalho de professores de cidades pequenas do Rio Grande do Sul. Rev Soc Bras de Fonoaudiol., v. 10, n. 2, p. 83-90, 2005.

SERVILHA, E. A. M.; MONTEIRO, Estratégias para obter a atenção discente no contexto universitário: o papel da voz do professor. Distúrb Comun, São Paulo, v. 19, n. 2, p. 225-235, agosto, 2007.

; PEREIRA, P. M. Condições de trabaIho, saúde e voz em professores universitários. Rev. Ciênc. Méd., Campinas, v. 17, n. 1, p. 21-31, jan/fev., 2008. 
; ROCCON, P. F. Relação entre voz e qualidade de vida em professores universitários. Rev. CEFAC. v. 11, n. 3, p. 440-448, Jul-Set, 2009.

; MESTRE, L. R. Adoecimento vocal em professores e estratégias para sua superação. Distúrb Comun, São Paulo, v. 22 n. 3, p. 231-239, 2010.

; ARBACH, M. P. Avaliação do efeito de assessoria vocal com professores universitários. Distúrb Comun, São Paulo, v. 25, n. 2, p. 211-218, agosto, 2013.

SIMÕES, M.; LATORRE, M. R. D. O. Prevalência de alteração vocal em educadoras e sua relação com a auto percepção. Rev. Saúde Pública. v. 40, n.6, p. 1013-1018, 2006.

; ___ Alteração vocal em professores: uma revisão. J Bras Fonoaudiol., v. 3, n. 11, p. 127-34, 2002.

SMITH, E. et al. Frequency and effects of teachers' voice problems. J. Voice, v. 11, n. 1, p. 81-7, 1997.

VIEIRA, A. C.; BEHLAU, M. Análise de voz e comunicação oral de professores de curso pré-vestibular. Rev Soc Bras Fonoaudiol., v. 14, n.3, p. 346-51, 2009.

VILKMAN, E. Ocupattional safety and health aspects of voice and speech professions. Folia Phoniatr. Logop, v. 56, n. 4, p. 220-53, 2004.

License information: This is an openaccess article distributed under the terms of the Creative Commons Attribution License, which permits unrestricted use, distribution, and reproduction in any medium, provided the original work is properly cited.

Artigo recebido em 02 de janeiro de 2016.

Avaliado em 04 de abril de 2016.

Aceito em 18 de julho de 2016.

Publicado em 03 de novembro de 2016.
Como citar este artigo (ABNT):

BATISTA, Eraldo Carlos; MATOS, Luís Alberto Lourenço de. O trabalho docente no ensino superior e a saúde vocal: um estudo de revisão bibliográfica. Estação Científica (UNIFAP), Macapá, v. 6, n. 2, p. 67-77, maio/ago. 2016. 